\title{
As elites da Justiça: instituições, profissões e poder na política da justiça brasileira
}

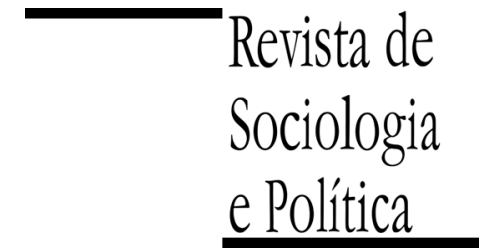

DOI 10.1590/1678-987314225206

\author{
Frederico de Almeida
}

\begin{abstract}
RESUMO
O presente trabalho busca sistematizar o referencial teórico utilizado em um estudo sobre as elites jurídicas e a política da justiça no Brasil. A partir de problemas metodológicos trazidos pela pesquisa empírica, o artigo busca apresentar as articulações feitas entre a sociologia das elites propriamente, os estudos de sociologia das profissões jurídicas e as análises institucionais da ciência política sobre o sistema de justiça para a identificação e a análise das elites jurídicas e de sua ação política ao nível da administração superior e da reforma do sistema de justiça no Brasil. A articulação desses referenciais teóricos foi possível a partir de uma confrontação entre as concepções de sistema de justiça e de campo jurídico. A partir da revisão da literatura dessas diferentes tradições teóricas e da ilustração dos problemas metodológicos por meio de conjunto de dados selecionados, conclui-se pela pertinência do uso da noção de campo jurídico como moldura teórica para se entender as distinções e hierarquizações de bases institucional, profissional e social que produzem elites da política da justiça no Brasil.
\end{abstract}

PALAVRAS-CHAVE: elites jurídicas; política da justiça; sistema de justiça; campo jurídico; reformas judiciais.

Recebido em 27 de Novembro de 2013. Aprovado em 26 de Agosto de 2014.

\section{Introdução ${ }^{1}$}

\footnotetext{
1 Este artigo é uma versão modificada do capítulo introdutório de minha tese de doutoramento (Almeida 2010a). Agradeço aos comentários de Flávio Heinz no colóquio Elites em diferentes escalas: teoria e metodologia no estudo de grupos dirigentes, onde uma primeira versão desse texto foi apresentada; e aos comentários dos pareceristas anônimos da Revista de Sociologia e Política à versão final.

${ }^{2}$ Para uma síntese dos resultados dessa pesquisa, ver Almeida (2010b).
}

$\mathrm{O}$ presente trabalho busca sistematizar o referencial teórico utilizado por mim em um estudo sobre as elites jurídicas e a política da justiça no Brasil $^{2}$. Partindo do objetivo inicial de identificar os atores políticos relevantes do processo de reforma do Judiciário no Brasil, aquela pesquisa logo se defrontou com algumas questões teóricas e empíricas que definiram o referencial teórico abaixo descrito.

O primeiro conjunto de questões decorreu de um aspecto essencialmente institucional do sistema de justiça estatal brasileiro: sua fragmentação federativa e multiprofissional, ou seja, uma estrutura constitucional que estabelece uma divisão do poder Judiciário entre justiça federal e justiças estaduais; a autonomia entre elas e de cada justiça estadual; uma organização estruturalmente simétrica do Ministério Público; a combinação entre autonomia política da Ordem dos Advogados do Brasil (OAB) e sua inserção no desenho constitucional do sistema de justiça. Esse aspecto institucional da organização da justiça estatal, que nos leva à imagem de vários sistemas de justiça (Falcão 2005), trouxe as seguintes questões para a pesquisa: como foi possível realizar a reforma do Judiciário de 2004 em um cenário de dificuldades institucionais de coordenação nacional de organizações e carreiras tão autonomizadas? Quais as lideranças e os processos políticos possíveis para uma ação de âmbito nacional no sentido da construção de uma agenda e de um processo político de aprovação e execução de uma reforma do Judiciário?

O segundo conjunto de questões decorreu de outro tipo de autonomia construída historicamente no interior do sistema de justiça, e que se sobrepõe e se confunde com as diversas autonomias decorrentes da fragmentação institu- 
cional colocada pelo desenho constitucional: a autonomia profissional, entendida no sentido da sociologia das profissões, construída como ideologia identitária e prática política de magistrados, membros do Ministério Público e advogados na demarcação de fronteiras entre si e entre eles e o Estado e o mundo da política (Bonelli 2002). A dimensão profissional dos grupos de juristas que administram a justiça estatal trouxe as seguintes questões para a pesquisa: como se deu a representação política dessas profissões no processo político da reforma do Judiciário? Como a demarcação de fronteiras entre esses grupos e entre eles e o mundo da política afetou suas estratégias de ação política em relação à reforma?

Por fim, um terceiro conjunto de questões decorreu da constatação, ao longo da pesquisa empírica, do protagonismo político de grupos de juristas que, embora tivessem inserções nas instituições e nas organizações profissionais do sistema de justiça, qualificavam sua atuação no processo político da reforma da justiça como intelectuais, como especialistas em uma dimensão específica da reforma do Judiciário que é a legislação processual, que define os ritos de resolução de conflitos por meio do qual agem instituições e profissionais da justiça. Essa dimensão da reforma da justiça no Brasil trouxe as seguintes questões: como entender o protagonismo de atores sem posição institucional superior, mas com grande influência nos processos políticos de reforma do Judiciário gestados e desenvolvidos no interior do Estado brasileiro? Qual a relação estabelecida entre esses atores e os atores cuja caracterização como atores políticos decorre de sua posição na estrutura institucional do sistema de justiça?

Esses conjuntos de questões levaram aquela pesquisa na direção de um estudo sobre elites: estava claro que o problema da liderança política da reforma em âmbito nacional só poderia ser enfrentado caso se passasse a considerar os atores jurídicos do processo como grupos dirigentes de um sistema com múltiplas divisões institucionais e profissionais. A fragmentação institucional do sistema de justiça, a dimensão profissional das carreiras jurídicas e seu discurso de autonomia, e o papel dos intelectuais com inserção nas reformas, contudo, levaram-nos a problematizar o referencial teórico das elites ou grupos dirigentes em face dos achados empíricos e das referências teóricas vindos de outros campos de estudos.

Este artigo busca, portanto, apresentar as articulações feitas entre a sociologia das elites propriamente dita, de um lado, e os estudos de sociologia das profissões jurídicas e as análises institucionais da ciência política sobre o sistema de justiça, por outro. A moldura teórica mais ampla encontrada para a articulação desses diferentes elementos teóricos foi o conceito de campo jurídico, de Pierre Bourdieu (2007a). Como demonstrarei abaixo, a ideia de um espaço social de agentes, posições e relações, constitutivas de distinções e visões de mundo próprias do direito, pareceu bastante útil para a integração dos aspectos institucionais e profissionais da organização da justiça estatal brasileira, bem como para compreender os processos de diferenciação e hierarquização que produzem grupos dominantes - as elites da justiça - capazes de impor discursos legítimos e práticas políticas para a administração superior e a reforma do aparato da justiça estatal.

\section{Campo jurídico e sistema de justiça}

Com maior ou menor rigor, com maior ou menor definição conceitual, as noções de campo jurídico e sistema de justiça vêm sendo utilizadas em diversos estudos de ciências sociais sobre o funcionamento da justiça no Brasil, seus agentes e suas instituições. De uma maneira bastante esquemática - e, consequentemente, um tanto imprecisa - é possível dizer que a noção de campo 
${ }^{3}$ Não se poder ignorar, também, a influência da expressão judicial system, utilizada em língua inglesa, e especialmente no Estados Unidos, como equivalente a "poder Judiciário", não só pelos cientistas políticas, como também pelos operadores do sistema. jurídico é mais comum em estudos de viés sociológico ou antropológico, ao passo que a de sistema de justiça é característica dos estudos políticoinstitucionais. Isso não quer dizer que não se verifique, na realidade, o uso combinado das duas expressões, ora tidas como sinônimos, ora como noções complementares - tal qual se percebe, por exemplo, nos estudos de Bonelli (1999b; 2002) e Sinhoretto (2011). Ainda que sob risco de certo preciosismo, serão dedicadas considerações a fim de esclarecer de que maneira buscou-se situar as instituições do chamado sistema de justiça no interior do campo jurídico, e a partir desse posicionamento, identificou-se o espaço de ação política de elites jurídicas especialmente dedicadas à administração superior e à reforma da justiça.

Segundo Sadek, cientista política e uma das principais mobilizadoras, no Brasil, da noção corrente de sistema de justiça ${ }^{3}$ nos trabalhos de orientação político-institucional:

"A constituição e o desenvolvimento de uma área temática centrada nas instituições que compõem o sistema de justiça correlacionam-se fortemente com o Estado de Direito, com a democracia formal e sua consolidação. [...] A agenda da Ciência Política como das demais Ciências Sociais só passou a incorporar estudos sobre o Judiciário e sobre as outras instituições que compõem o sistema de justiça nos anos de 1990, quando o regime democrático passou a ser considerado um valor em si mesmo e quando os efeitos da Constituição de 1988 tornaram-se visíveis" (Sadek 2002, p. 236).

Prossegue a autora:

"Entendemos por sistema de justiça o conjunto de instituições estatais encarregadas de garantir os preceitos constitucionais, de aplicar a lei e de distribuir justiça. [...] [A]o se constituir como uma área relativamente autônoma, tem invocado e chamado para si questões anteriormente tratadas por outras sociologias especializadas e outras disciplinas, quer do Direito quer das Ciências Sociais e da História. Mas, ao incorporar essas questões, transforma-as, examinado-as sob uma ótica distinta. Isto é, propõe que as análises sobre aqueles temas tenham por eixo ou fio condutor as instituições judiciais" (idem, p. 237).

Em outra passagem do mesmo artigo, Sadek reforça dois aspectos sugeridos nas passagens transcritas acima, centrais na formulação do conceito de sistema de justiça: seu caráter institucional-formal e sua vinculação à organização jurídico-constitucional do poder. Afirma a autora:

“A Constituição de 1988 e os papéis atribuídos ao Judiciário, ao Ministério Público, à Defensoria Pública, à Procuradoria da República, à Advocacia Geral da União, às polícias, aos advogados, enfim aos operadores do Direito, representam uma mudança radical, não apenas no perfil destas instituições e de seus integrantes, mas também em suas possibilidades de atuação na arena política e de envolvimento com questões públicas. [...] Esse Judiciário, com baixíssima realidade política, ganhou vitalidade na ordem democrática ou, ao menos, foram-lhe propiciadas condições de romper com o encapsulamento em que vinha vivendo desde suas origens. No que se refere às demais instituições do sistema de justiça, a conversão foi ainda maior: conquistaram recursos de poder e um espaço que extrapola (em excesso, diriam alguns) os limites de funções exclusivamente judiciais" (idem, pp. 253-254).

De fato, uma análise formal do modelo institucional-constitucional do sistema de justiça seria, do ponto de vista de qualquer análise política, um passo importante, se não o primeiro, de uma investigação sobre a justiça estatal de qualquer país. O objetivo, como já dito, é agregar à análise da organização da justiça brasileira, a partir de seu desenho constitucional, considerações relacionadas a outras formas de estruturação e organização do poder que não somente aquelas previstas nos desenhos institucionais e nas constituições políticas, e que será buscada justamente na teoria dos campos sociais, de Bourdieu. 
${ }^{4}$ Para importantes revisões da literatura de ciências sociais sobre o funcionamento da justiça no Brasil, seus desenvolvimentos e divisões disciplinares, ver Junqueira (1996) e Sadek (2002). Por fim, importante mencionar o esforço de sistematização da literatura levado a cabo por Sinhoretto (2011), que faz uma crítica das revisões feitas por Junqueira e Sadek.
Essas considerações não são de todo ausentes nas análises institucionais, já que, como afirma Sadek (idem), a delimitação do chamado sistema de justiça tem por objetivo constituir-se em uma linha de análise, um parâmetro de organização de uma vasta produção de ciência social sobre o funcionamento da justiça estatal em torno de um objeto comum, qual seja, a qualidade de nossa democracia, aferível também por seu desempenho judicial - ou, em outras palavras, pelo desempenho de suas instituições de justiça. Daí, conforme Sadek sugere na transcrição acima, a ideia de sistema de justiça como eixo, ou fio condutor, de análises desenvolvidas por diferentes disciplinas das ciências sociais, bem como da história e do direito, em torno de um objeto que "é mais amplo do que o poder judiciário" (Sadek 1999, p. 11).

Buscou-se avançar, portanto, na construção de uma moldura teórica mais abrangente, que possa ser aplicada a outros objetos de pesquisa sobre a administração da justiça estatal brasileira e que permita a integração de variáveis sociológicas à análise institucional, possibilitando um diálogo metodologicamente estruturado de diferentes vertentes da produção da ciência social brasileira sobre o funcionamento da justiça estatal ${ }^{4}$. Nessa proposta metodológica, portanto, variáveis sociológicas e institucionais articulam-se desde o primeiro momento do trabalho de pesquisa, ou seja, desde o momento inicial de formulação das primeiras hipóteses de investigação, nas quais a origem, o exercício e a distribuição do poder no interior do sistema de justiça devem necessariamente considerar processos e fenômenos de origem social e simbólica (mais especificamente, aqueles relacionados às divisões de classe, gênero e prestígio), bem como aqueles decorrentes das funções e divisões político-institucionais (mais especificamente, aqueles relacionados ao desenho constitucional formal e às funções e denominações oficiais das instituições e dos agentes do sistema). Para tanto, parte-se dos estudos de Sadek e seus colaboradores sobre o sistema de justiça (Sadek 1999; 2001; 2002; 2003; 2004a; 2004b; 2006; Sadek \& Arantes 2001; Sadek \& Dantas 2001; Sadek \& Cavalcante 2003), para, por meio de um diálogo com uma ampla literatura sobre o funcionamento das instituições de justiça no Brasil, construir um objeto (a política da justiça, ou seja, o espaço de agentes e ações políticas voltadas para a administração superior e a reforma da justiça estatal) que permita compreender as origens, a organização e a distribuição do poder de direção e controle da administração da justiça estatal.

Da mesma forma como a mera listagem de posições institucionais serviria para a identificação das elites jurídicas, ela serviria também para a delimitação formal do espaço institucional do poder de administração da justiça estatal. Entretanto, como sugerido acima, acredita-se que o poder da administração da justiça estatal não é exercido e delimitado apenas por posições e arenas institucionais; em outras palavras, o espaço de circulação e exercício desse poder de direção superior e reforma da justiça é estruturado a partir da concentração de diversas formas de capitais - não apenas institucionais, mas também sociais e políticos, como demonstrado a partir das análises de trajetórias com foco em variáveis como experiências profissionais e políticas, gênero e faculdades de origem - e, principalmente, da articulação que essas estruturas de capitais compartilhados permitem entre diferentes posições institucionais, ocupadas por membros com trajetórias e perfis semelhantes. Além disso, como demonstrado na análise do poder dos intelectuais com atuação na reforma do Judiciário, esse espaço de poder inclui, também, posições à margem do organograma do sistema de justiça - embora as comissões de reforma processual, no âmbito do Executivo e do Legislativo, e de um conselho de pesquisas judiciárias, no âmbito do Conselho Nacional de Justiça, apontem para algum grau de institucionalização formal dessas posições de poder.

A existência desse espaço de poder, no qual transitam agentes com estruturas de capitais semelhantes, ajuda a entender como se dá a unidade política 
nacional de um sistema de justiça formalmente fragmentado, tendo em vista sua estrutura federativa e dual. Nesse aspecto, a criação dos Conselhos Nacionais de Justiça (CNJ) e do Ministério Público (CNMP), bem como os mecanismos processuais que aumentaram o poder jurisdicional do Supremo Tribunal Federal (súmulas vinculantes e repercussão geral dos recursos), apenas consolidaram, pela via da institucionalização no aparato estatal da administração da justiça, um poder já concentrado em um pólo nacional dominante, estruturado em torno das posições institucionais do Supremo Tribunal Federal (STF), do Superior Tribunal de Justiça (STJ), da Procuradoria-Geral da República (PGR) e da Ordem dos Advogados do Brasil (OAB) e de suas relações com as cúpulas dos sistemas estaduais e federal de justiça, bem como de suas alianças com grupos intelectuais tão bem delimitados e concentrados como os especialistas em direito processual.

Para Bourdieu (2007a), o processo de institucionalização (ou simplesmente instituição) é caracterizado como um acúmulo lento de conquistas históricas, fruto da ação de agentes em disputa por princípios de divisão e organização do mundo social, capaz de restringir as possibilidades de ação e transformação do mundo pela incorporação e reificação contínua da história. Segundo o autor:

\begin{abstract}
"O processo de instituição, de estabelecimento, quer dizer, a objetivação e a incorporação como acumulação nas coisas e nos corpos de um conjunto de conquistas históricas, que trazem a marca das suas condições de produção e que tendem a gerar as condições da sua própria reprodução (quanto mais não pelo efeito de demonstração e imposição das necessidades que um bem exerce unicamente pela sua existência), aniquila continuamente possíveis laterais. À medida que a história avança, estes possíveis tornam-se cada vez mais improváveis, mais difíceis de realizar, porque a sua passagem à existência suporia a destruição, a neutralização ou a reconversão de uma parte maior ou menor da herança histórica - que é também um capital -, e mesmo mais difíceis de pensar, porque os esquemas de pensamento e de percepção são, em cada momento, produto das opções anteriores transformadas em coisas" (idem, p. 101).
\end{abstract}

A compreensão conjunta de processos formais/estatais e informais/societais de institucionalização para a construção do campo e do objeto de estudo é possível a partir da ideia de que as estruturas do campo têm diferentes pesos relativos (idem), tendo o Estado um papel especial na legitimação e oficialização de divisões e hierarquias social e politicamente construídas (Bourdieu 1989); além disso, segundo Bourdieu (2007a), essa compreensão conjunta de processos temporalmente distintos de institucionalização deve constituir-se no foco de análise do cientista social, apesar de muitas vezes reproduzirem-se em tempos históricos diversos.

Bourdieu é um dos autores da teoria social contemporânea dedicados ao esforço teórico de conciliação entre ação e estrutura na explicação dos fenômenos sociais (Cohen 1999; Vandenbergue 2006). Seu conceito de habitus - uma visão de mundo compartilhada por indivíduos com características sociais comuns, produzida pela ação de mecanismos como a educação formal e familiar, ritos de passagem e práticas de sociabilidade que incutem nos indivíduos as estruturas objetivas de poder no campo e na sociedade e que definem suas próprias posições (e posturas, práticas, gestual etc.) nesse campo (Bourdieu 2007a; 2007b) -, associado ao conceito de campo - um espaço social de estruturas e agentes com características comuns e que disputam um tipo de capital próprio desse espaço, como o capital político ou o capital jurídico (Bourdieu 2007a; 2007b) -, fornece uma importante teoria da ação e, ao mesmo tempo, uma interessante "solução" para o aparente dilema ação vs. estrutura na teoria social $^{5}$, em geral, e para a análise institucional, especificamente. O aprofundamento da análise do habitus confere dinâmica e substância ao campo como objeto de pesquisa ao identificar na ação dos agentes tanto a história incor-
5 Sobre esse e outros dilemas (ou "encruzilhadas") fundamentais da ciência 
social, ver Tilly (2004).

Buscou-se enfrentar cada um desses dilemas, de uma forma mais detalhada, no capítulo introdutório de minha tese de doutoramento (Almeida 2010a) porada em suas trajetórias individuais como a história reificada nas instituições, ou seja, ao revelar a presença de elementos subjetivos e objetivos que determinam as estratégias, concebidas como o senso prático dessa ação, empiricamente verificado no caso concreto em estudo (Lamaison \& Bourdieu 1986). Segundo Bourdieu (2007b, p. 164):

"A teoria da ação que proponho (com a noção de habitus) implica dizer que a maior parte das ações humanas tem por base algo diferente da intenção, isto é, disposições adquiridas que fazem com que a ação possa e deva ser interpretada como orientada em direção a tal ou qual fim, sem que se possa, entretanto, dizer que ela tenha por princípio a busca consciente desse objetivo [...]. O melhor exemplo de disposição é, sem dúvida, o sentido do jogo: o jogador, tendo interiorizado profundamente as regularidades de um jogo, faz o que faz no momento em que é preciso fazê-lo, sem ter a necessidade de colocar explicitamente como finalidade o que deve fazer. Ele não tem necessidade de saber conscientemente o que faz para fazê-lo, e menos ainda de se perguntar explicitamente (a não ser em algumas situações críticas) o que os outros podem fazer em resposta, como faz crer a visão do jogo de xadrez ou de bridge que alguns economistas (especialmente quando aderem à teoria dos jogos) atribuem aos agentes".

O campo, porém, não é uma estrutura politicamente neutra; ao contrário, é nele que são produzidas formas de dominação específicas, bem como se reproduzem formas de dominação próprias de outros campos sociais, que se traduzem na lógica específica de cada um desses espaços sociais. O problema da dominação está na base dos estudos de Weber sobre a burocracia (Tragtenberg 1974; Giddens 1998) e também da análise marxista de classes (Miliband 1999); o trabalho de Bourdieu, no que se refere à dominação, pode ser considerado uma forma de conciliação entre essas duas tradições, síntese possível por meio de sua teoria dos campos do poder e pela análise do poder a partir das estruturas e dos volumes de diversos capitais, que resultam em diferentes posições de poder (incluindo a de classe), e na produção cultural como meio de violência e dominação simbólica.

Para Bourdieu, ao menos em uma etapa inicial do projeto científico, a construção de um campo como objeto de pesquisa deve se dar como construção prévia do esquema de relações dos agentes e instituições objeto do estudo, ou seja, entre as posições do campo. Essa etapa define a problemática do campo a partir de um modelo, não no sentido de regularidades pré-definidas como "leis" ou formalizadas matematicamente, mas sim no sentido de proposições a serem testadas, que antecedem a experimentação, "um sistema coerente de relações, que deve ser posto à prova como tal” (Bourdieu 2007a, p. 32). Após a reconstrução da lógica do campo, por meio de uma "interpretação das causas estruturais que escapam à consciência” dos agentes (Thiry-Cherques 2006, p. 45), obedecendo a um trabalho de dedução e indução que corrige permanentemente o esquema inicial de análise, conferindo-lhe "substância" com a incorporação dos resultados de pesquisa empírica, e do habitus do campo, ou seja, a congruência de elementos subjetivos e objetivos que determinam as estratégias dessa ação, a matriz relacional inicial de análise deve ser corrigida, buscando-se o que Thiry-Cherques (idem, p. 50) denomina síntese da problemática geral do campo.

Essa etapa final encaminha o trabalho de pesquisa para suas conclusões em termos de recolocar os problemas iniciais, buscando respostas às questões por ele colocadas, teorias que o expliquem e novos desdobramentos e hipóteses de pesquisa futura a partir desse novo estado de conhecimento do campo. $\mathrm{O}$ conhecimento da problemática do campo orienta o analista para a identificação do "senso do jogo" que estrutura as práticas naquele campo e do próprio trabalho de codificação e normatização social que produz as regras e as regularidades imediatamente apreensíveis pelo cientista social. 
${ }^{6}$ Ver o capítulo 4 de minha tese de doutoramento (Almeida, 2010a).
A teoria dos campos tem, portanto, caráter essencialmente metodológico e, nas palavras de Bourdieu (2007a, p. 31), "o limite de um campo é o limite de seus efeitos, ou, em outro sentido, um agente ou uma instituição faz parte de um campo na medida em que nele sofre efeitos ou nele os produz" - o que, de acordo com o programa de pesquisa escolhido, só se define ao final da pesquisa.

Nesse sentido, a opção por mesclar a análise de processos históricos de longo prazo - relacionados com a institucionalização do campo acadêmico em direito e das estruturas burocráticas e profissionais da justiça estatal - com a reconstrução de processos históricos conjunturais -, mais especificamente o primeiro ciclo da reforma do Judiciário de 2003 a 2004 e os conflitos conjunturais entre profissões e posições hierárquicas do campo jurídico em torno de fronteiras entre grupos e de nomeações para tribunais superiores ${ }^{6}-$, teve por objetivo justamente compreender a interação entre indivíduos, e entre eles e a estrutura social em dois contextos diversos, nos quais os horizontes das estratégias e tomadas de decisão diferem no tempo e no grau de consciência da ação. Assim, não se acredita descabido afirmar que estratégias, no sentido dado por Bourdieu - ou seja, de ações semiconscientes ou inconscientes, adotadas conforme o "senso do jogo" ou o habitus da posição social do agente -, sejam melhor apreensíveis, na análise social, na reconstrução das trajetórias de longo prazo que definem as posições dos agentes no campo jurídico e dos padrões de conflito e interação entre os diversos grupos profissionais de juristas, principalmente quando se analisam os deslocamentos intergeracionais de um mesmo grupo de elite. Por outro lado, também não parece equivocado afirmar que, na análise da ação dos grupos de elites jurídicas no processo político conjuntural da reforma do Judiciário e dos conflitos interprofissionais e hierárquicos, analidados em Almeida (2010a), estejam presentes outras estratégias, no sentido dado pelos adeptos da escolha racional, ou seja, de cálculos conscientes e racionais. Sobre esse ponto, em especial, tecer-se-á mais algumas considerações adiante, ao discorrer-se sobre o papel das elites em processos conjunturais.

Em suma, o importante de se apreender dessa escolha metodológica inicial é a concepção do poder como resultado de processos históricos e relacionais, nos quais agentes disputam posições tendo por recurso suas próprias quantidades de poder simbólico (seus capitais), em um contexto estruturado (o campo) e estruturante da ação política (por meio do habitus), ele próprio capaz de produzir novas formas e posições de poder. Assim, se é verdade que o Estado é uma organização caracterizada pelo monopólio do uso legítimo da violência, nos termos weberianos, é também verdade que esse monopólio se apresenta como uma reivindicação (Weber 1972, p. 56), um processo no qual a tendência de concentração do poder pelo Estado se dá em disputa e relação com os poderes "privados" - ou seja, um Estado "constituído como campo de forças e campo de lutas orientados para o monopólio da manipulação legítima dos bens públicos" (Bourdieu 2005, p. 41). No caso de minha pesquisa sobre as elites jurídicas brasileiras, esse referencial me permitiu situar a política da administração superior e da reforma da justiça brasileira para além das instituições formais do sistema de justiça, bem como identificar suas elites para além dos detentores oficiais de cargos públicos naquelas instituições.

\section{Os juristas como profissionais}

Outra perspectiva teórica que orientou estudos prévios sobre as elites jurídicas e a administração da justiça estatal (Almeida 2010a; 2010b; 2012) foi a da sociologia das profissões, especialmente da maneira como está nos estudos de Freidson (1996; 1998) e de Rueschemeyer (1964; 1977; 1986). Embora não se ignore a multiplicidade de abordagens sociológicas sobre as profissões e o 
${ }^{7}$ Sobre a profissionalização do trabalho jurídico e suas relações com o Estado brasileiro, ver capítulo 6 de minha tese de doutoramento (Almeida 2010a). profissionalismo (Diniz 1996; Coelho 1999; Bonelli 1999a), creio que os autores escolhidos, em especial Freidson, enfrentam temas que são comuns ao debate mais amplo da sociologia das profissões, ao mesmo tempo em que incluem, em suas análises, elementos relativamente consensuais na caracterização sociológica das profissões: $(i)$ sua constituição como grupo social e político a partir de um projeto político de autogoverno; (ii) a exigência de diploma de nível superior, o credencialismo e o controle sobre o exercício profissional monopolizado pelo grupo; ( iii) o papel da liderança profissional na condução daquele projeto político e na interação com o Estado, o mercado e a sociedade na conquista e manutenção de seu monopólio profissional; (iv) a diferenciação em relação a outras formas de organização do trabalho, como a burocracia e a livre concorrência do mercado.

Entendida, portanto, em perspectiva dinâmica, a profissionalização pode ser definida então como o processo pelo qual uma ocupação empreende um projeto político de conquista de um abrigo estável no mercado de trabalho, caracterizado por negociações e conflitos com consumidores, ocupações correlatas e principalmente o Estado na legitimação social e política de sua expertise, na definição de competências e títulos distintivos de seu conhecimento especializado e de sua jurisdição e na construção de artifícios institucionais de autogoverno e credencialismo dos pares (Rueschemeyer 1986; Freidson 1996; 1998).

Todas essas características estão presentes, em maior ou menor grau, na organização dos juristas brasileiros analisados em Almeida (2010a) - mesmo de magistrados e membros do Ministério Público que, ao contrário da advocacia (mais próxima do tipo-ideal de "profissão liberal"), organizam-se como carreiras de Estado. Aliás, acredita-se que é a partir da dinâmica dos conflitos entre sua organização burocrática (ligada ao Estado e sujeita a algum grau de controle hierárquico administrativo) e suas características propriamente profissionais (a autonomia de suas funções e o grau de controle próprio sobre o recrutamento e o exercício profissional) que se pode compreender a constituição da magistratura e do Ministério Público, bem como de suas associações representativas, como atores políticos relevantes na política da administração e reforma da justiça. Da mesma forma, mesmo a advocacia e a Ordem dos Advogados do Brasil, mais próximas do modelo de organização profissional "pura" (ou seja, organizada "fora" do Estado), não podem ter seu poder e sua atuação política explicadas sem recurso à sua relação com o Estado, seja por sua origem corporativa, seja pelos trânsitos de suas elites pelo campo político e pelo campo jurídico ${ }^{7}$.

Embora nem sempre na chave teórica de autores consagrados e propriamente identificados à sociologia das profissões (como Freidson, Terence Halliday e Magali Larson), mas especialmente no que se refere à sociologia das profissões jurídicas, merecem destaque - além dos trabalhos já citados de Freidson e Rueschemeyer, que têm nos advogados (ou lawyers) objetos preferenciais de estudo - o trabalho comparativo de Abel (1982); o estudo de Ellmann (1992) sobre os advogados de interesse público e a mobilização de causas coletivas nos Estados Unidos; a pesquisa de Heinz, Nelson e Laumann (2001) sobre a diversificação das práticas jurídicas de advogados e escritórios de Chicago; a coletânea de artigos organizada por Cummings (2011) sobre o paradoxo das profissões jurídicas, entre sua função pública de realização da justiça e os aspectos mercantis de sua lógica de funcionamento como prestação de serviço. Estabelecendo uma articulação entre a sociologia do campo jurídico de Bourdieu e uma sociologia das profissões jurídicas (ou dos juristas), é possível citar, ainda, os trabalhos de Yves Dezalay (Dezalay 1991; Dezalay \& Trubek 1996; Dezalay \& Garth 2000; 2002), que enfocam o papel do conhe- 
cimento especializado dos juristas nas transformações do Estado e do poder na Europa e na América Latina.

No que se refere à sociologia das profissões jurídicas no Brasil, a principal referência foram os estudos coordenados ou com participação de Maria da Glória Bonelli (Bonelli 1999b; 2002; 2003; 2008; Bonelli, Oliveira \& Martins 2006; Cunha et al., 2007; Bonelli et al. 2008). Esses estudos buscaram reconstruir o percurso por meio do qual magistrados, membros do Ministério Público, advogados e delegados de polícia construíram seus projetos políticos de autonomia profissional e suas próprias ideologias do profissionalismo, em conflitos e negociações com o Estado, o mercado e os demais grupos profissionais; identificou, ainda, as clivagens internas que, em muitos casos, marcam as trajetórias de institucionalização e construção dos projetos profissionais desses grupos.

Por fim, na mesma linha dos trabalhos de Yves Dezalay, já citados, teve-se por referência também os estudos de Engelmann (2006a; 2006b) sobre a institucionalização e a diversificação das carreiras jurídicas e as lutas entre grupos profissionais no campo jurídico brasileiro.

Como dito acima, esse referencial teórico específico mostrou-se útil na medida em que pode se caracterizar os juristas e suas elites como membros de grupos profissionais, no sentido em que são definidas as profissões por sua sociologia específica e no sentido em que assim são caracterizadas as profissões jurídicas brasileiras pela ampla produção nacional baseada nesse referencial teórico. O recurso à sociologia das profissões ajudou a entender-se a evolução histórica da relação entre direito e política na constituição desses grupos profissionais, mais especificamente, no sentido de uma progressiva - mas nunca total - diferenciação de atividades estritamente profissionais das atividades tipicamente políticas. O Gráfico 1 mostra como a passagem por cargos políticos legislativos e executivos diminui, mas não desaparece totalmente na composição social de um importante grupo das elites jurídicas brasileiras, que são os ministros do STF.

Gráfico 1 - Porcentagens de ministros do Supremo Tribunal Federal com passagens por cargos políticos legislativos e executivos (Brasil, 1827 a 2008)

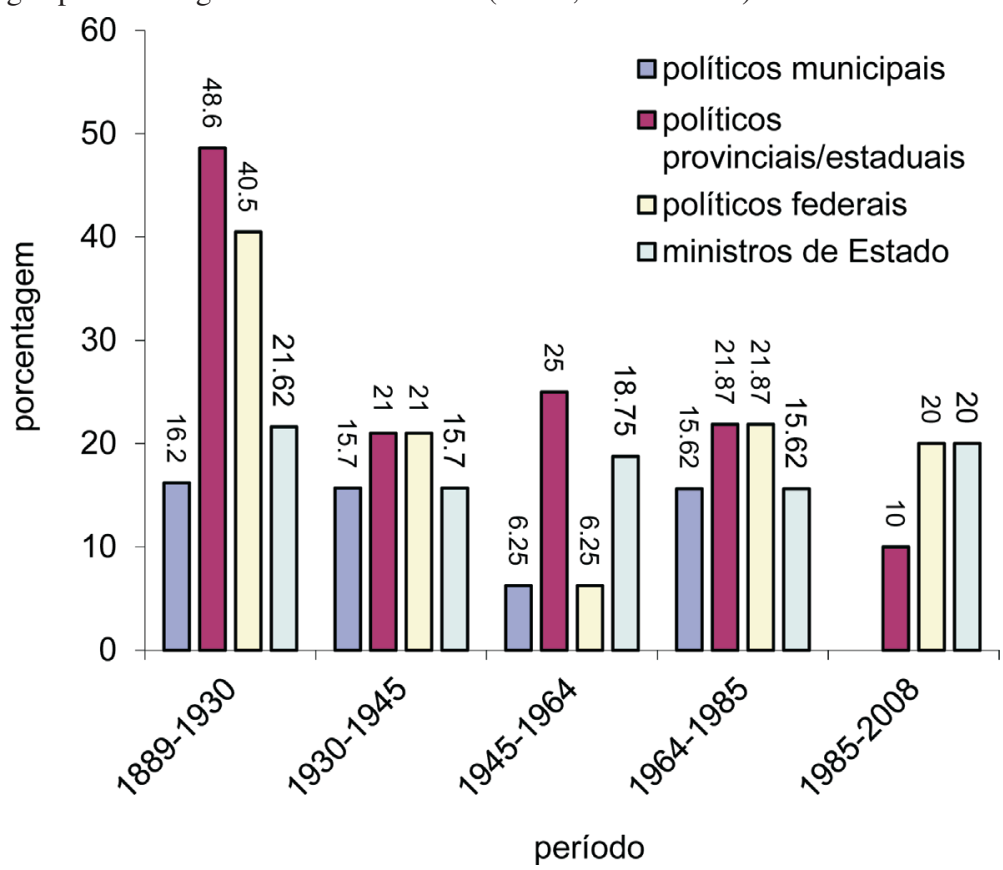

Fonte: Almeida (2010a), a partir de Supremo Tribunal Federal. 
A perspectiva da sociologia das profissões ajudou, também, na identificação dos conflitos interprofissionais do campo jurídico brasileiro, como definidores de clivagens e hierarquizações entre profissões ao nível das elites jurídicas, e na identificação da importância do associativismo profissional para a formação de capital político próprio desse campo. O Gráfico 2 é ilustrativo do primeiro aspecto, ao demonstrar como certas experiências profissionais são mais importantes do que outras na construção de trajetórias de juristas que chegam ao STF; o Gráfico 3, por sua vez, demonstra a importância da experiência como liderança associativa no acúmulo de capital político próprio da dinâmica de representação dos grupos de juristas em disputa no campo jurídico brasileiro.

\section{Os juristas como elite e a elite dos juristas}

A terceira perspectiva que orientou o estudo sobre as elites jurídicas e a política da administração e da reforma da justiça estatal (Almeida 2010a) foi,

Gráfico 2 - Porcentagens de ministros do Supremo Tribunal Federal de acordo as trajetórias profissionais (Brasil, 1827 a 2008)

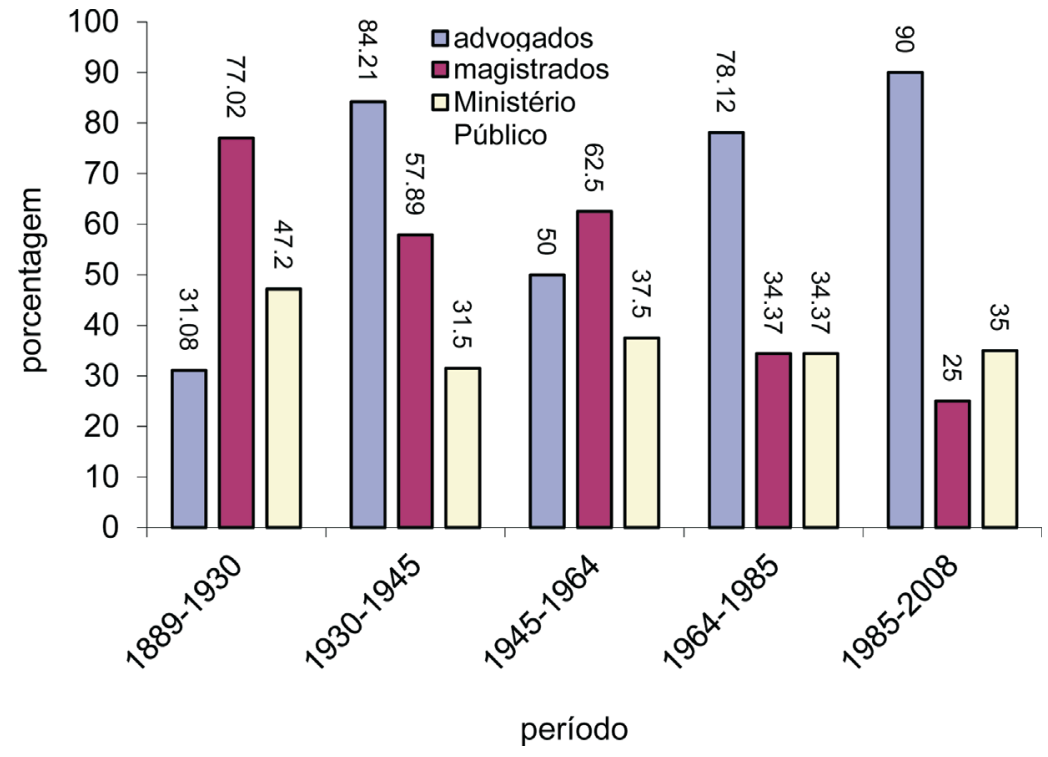

Fonte: Almeida (2010a), a partir de Supremo Tribunal Federal.

Gráfico 3 - Porcentagens de ministros do Supremo Tribunal Federal com passagens por cargos de liderança corporativa (Brasil, 1827 a 2008)

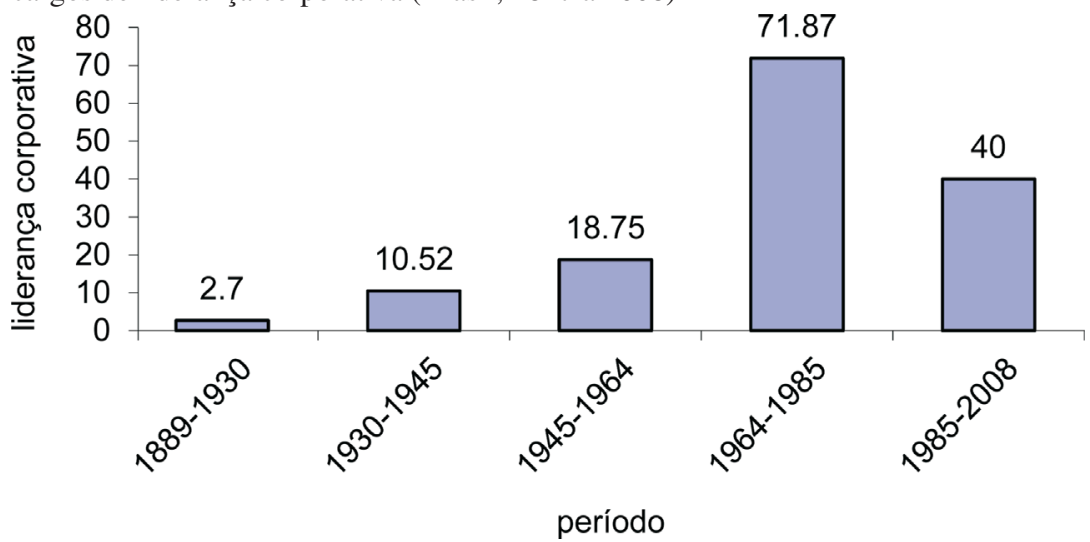

Fonte: Almeida (2010a), a partir de Supremo Tribunal Federal. 
obviamente, a da sociologia das elites. Ao estabelecer interlocução com a sociologia das elites, buscou-se situar aquele estudo no esforço de retomada desse tema pelas ciências sociais brasileiras (Perissinotto \& Codato 2008) e identificar bases para a comparação das elites jurídicas com outras elites sociais, econômicas, intelectuais, políticas e administrativas no Brasil.

A opção pela abordagem das elites justifica-se, segundo José Murilo de Carvalho (2007, p. 25), porque "uma das vantagens das abordagens clássicas do fenômeno das elites políticas é a vinculação que fazem entre elite e dinâmica social". O autor identifica dois métodos de análise das elites desenvolvidos pela literatura: o primeiro, de posição, identifica a elite nas posições formais de poder, o que incluiria os cargos eletivos e burocráticos do Estado e das organizações econômicas e profissionais; o segundo, de decisão, identifica a elite nos grupos e nas pessoas que exercem poder real, mais do que institucional-formal, na estrutura social, podendo a fonte desse poder ser de natureza diversa da estatal, ou seja, pode ser de natureza social, econômica e cultural. Nesse aspecto, a opção adotada em minha pesquisa pode se localizar entre aqueles estudos que, segundo Carvalho, buscam articular os dois métodos na definição das elites, já que, de acordo com Bourdieu (2007b), as posições de elite são determinadas pela combinação cumulativa de capitais econômicos, culturais, e dos capitais próprios de cada campo (como o jurídico, por exemplo), que deve ser analisada em três dimensões: (I) a distribuição dos agentes no campo de acordo com o volume global do capital possuído, de qualquer modalidade; (II) o peso relativo de um ou outro capital na estrutura do capital global (com destaque para as relações entre capitais econômicos e culturais); e (III) a evolução, no tempo, do volume e da estrutura desses capitais, perceptível na reconstrução das trajetórias dos agentes no campo.

Para além da contribuição específica de Bourdieu, contudo, a leitura de trabalhos diversos sobre diferentes aspectos ou grupos de elite expõe elementos comuns dessa tradição de estudos, que ajudaram na orientação de minha pesquisa. O primeiro deles, como já sugerido acima, é a articulação necessária que se deve buscar, na análise dos grupos de elites, entre esses indivíduos e grupos e a própria estrutura social, a partir da verificação das divisões sociais que permitem o destacamento e a identificação de um ou mais grupos como elites. Essa orientação serve para advertir o analista das elites sobre os riscos do mal uso do método prosopográfico ${ }^{8}$ e para forçá-lo a considerar, na identificação dos atributos comuns de grupos sociais de elites, a partir das trajetórias individuais, a incidência de elementos estruturais e da relação entre agentes e estruturas na constituição das relações de poder e dominação, e de legitimação dessas relações num dado contexto (campo) social (Montagner 2007; Perissinotto \& Codato 2008).

Em outras palavras, o risco do mal uso do método estritamente prosopográfico, que a metodologia do campo previne, é o da ênfase excessiva que se possa dar aos atributos individuais como sendo efetivamente pessoais, essencialmente ligados aos sujeitos, sejam esses atributos naturais ou adquiridos. $\mathrm{O}$ que a análise sociológica da trajetória dos indivíduos deve revelar, ao contrário, é a incorporação das estruturas objetivas nos indivíduos e nos esquemas subjetivos de percepção e representação, de construção de identidades e de ação social (Bourdieu 2007a). Segundo F.M. Heinz (2006, p. 8), "trata-se de compreender, através da análise mais 'fina' dos atores situados no topo da hierarquia social, a complexidade de suas relações e de seus laços objetivos com o conjunto ou com setores da sociedade".

Nesse sentido, para ser completado, esse tipo de análise deve também relacionar a compreensão dessa história incorporada nos sujeitos à compreensão da história reificada nas estruturas, ou seja, da objetividade das estru- 
turas sociais, em perspectiva histórica (Bourdieu 2007a). No caso de Almeida (2010a), buscou-se compreender não só como os juristas se inserem e são produzidos a partir da estrutura social brasileira, mas também como uma minoria de juristas domina os demais, no interior do campo jurídico, no espaço político da administração superior e da reforma da justiça estatal. Esse esforço obrigou-nos a considerar, portanto, os desenvolvimentos da estrutura social e das instituições políticas brasileiras e a incidência de fatores relacionados a classes sociais, raças, gênero, burocratização etc. nas trajetórias desses agentes e na estruturação daquele espaço de dominância e controle político da justiça estatal. Veja-se, a título ilustrativo, como o processo de feminização das carreiras jurídicas brasileiras, apontado por Werneck Vianna et al. (1997) como indicativo das mudanças mais amplas da estrutura social brasileira, têm seus efeitos contidos ao nível das elites da justiça estatal (Gráfico 4).

Uma segunda orientação que decorre da leitura de diversos trabalhos sobre elites, e que está associada à anterior, diz respeito às divisões e hierarquias presentes no interior da própria elite (Bottomore 1965), para além da clássica distinção entre elites e não-elites formulada por Vilfredo Pareto (1966). Em Almeida (2010a), buscou-se identificar conflitos entre subgrupos de elites jurídicas na composição das instâncias superiores de liderança da administração da justiça estatal, sejam esses conflitos estabelecidos entre bases e cúpulas de organizações profissionais, sejam eles deflagrados entre diferentes grupos profissionais que vivenciam situações de dominação entre ocupações correlatas (Freidson 1998). A análise da institucionalização do CNJ como um espaço de lutas entre grupos de elites e entre elites e não-elites parece emblemática dessa afirmação: o Gráfico 5 demonstra como profissionais de "baixo escalão", associações de bases corporativas e ocupações subalternas do sistema de justiça foram os principais demandantes do CNJ nas sessões analisadas; o Gráfico 6 demonstra como os principais demandados, nos procedimentos administrativos analisados nessas mesmas sessões, foram as cúpulas de tribunais do poder Judiciário.

Essas considerações sobre divisão entre elite e não elite e sobre as hierarquias e divisões no interior das elites nos levam à terceira contribuição dos estudos de elite para meu próprio trabalho, qual seja a questão da circulação e permeabilidade das elites (Bottomore 1965; Ferreira 2001). Nesse sentido, buscou-se identificar como determinados espaços e estruturas institucionais permitem certo grau de circulação de grupos de juristas entre posições de elite, e

Gráfico 4 - Porcentagens de homens e mulheres entre magistrados, por grau de jurisdição (Brasil, 2005)

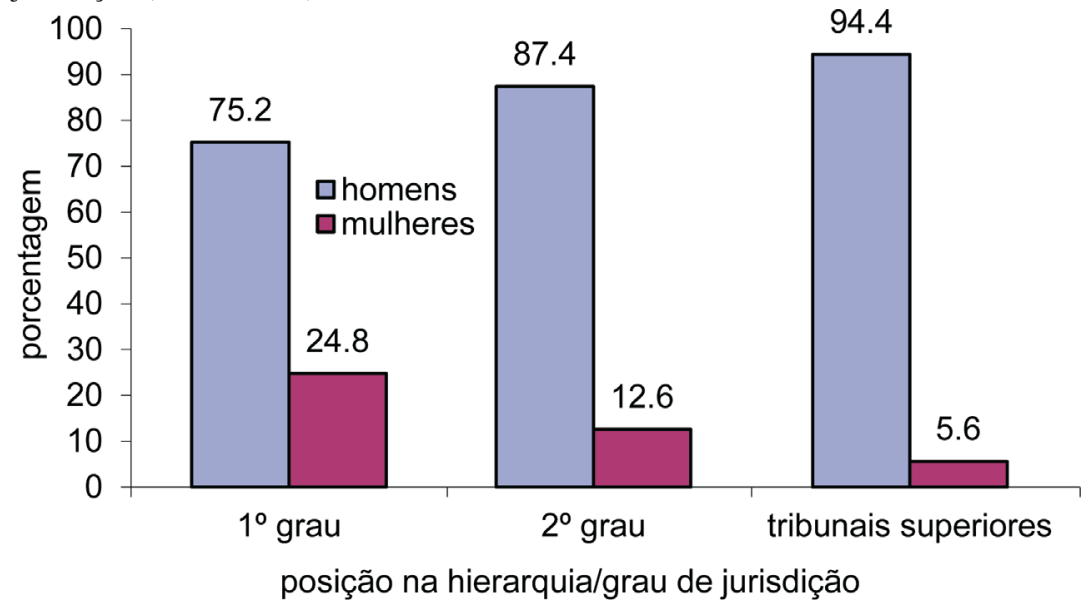

Fonte: Sadek (2006). 
Gráfico 5 - Porcentagens de procedimentos de controle administrativos e de pedidos de providências, somados, na pauta da $46^{a}$, da $68^{\mathrm{a}}$ e da $88^{\mathrm{a}}$ sessões ordinárias do Conselho Nacional de Justiça, por tipo de requerente (Brasil, 2007, 2008 e 2009)
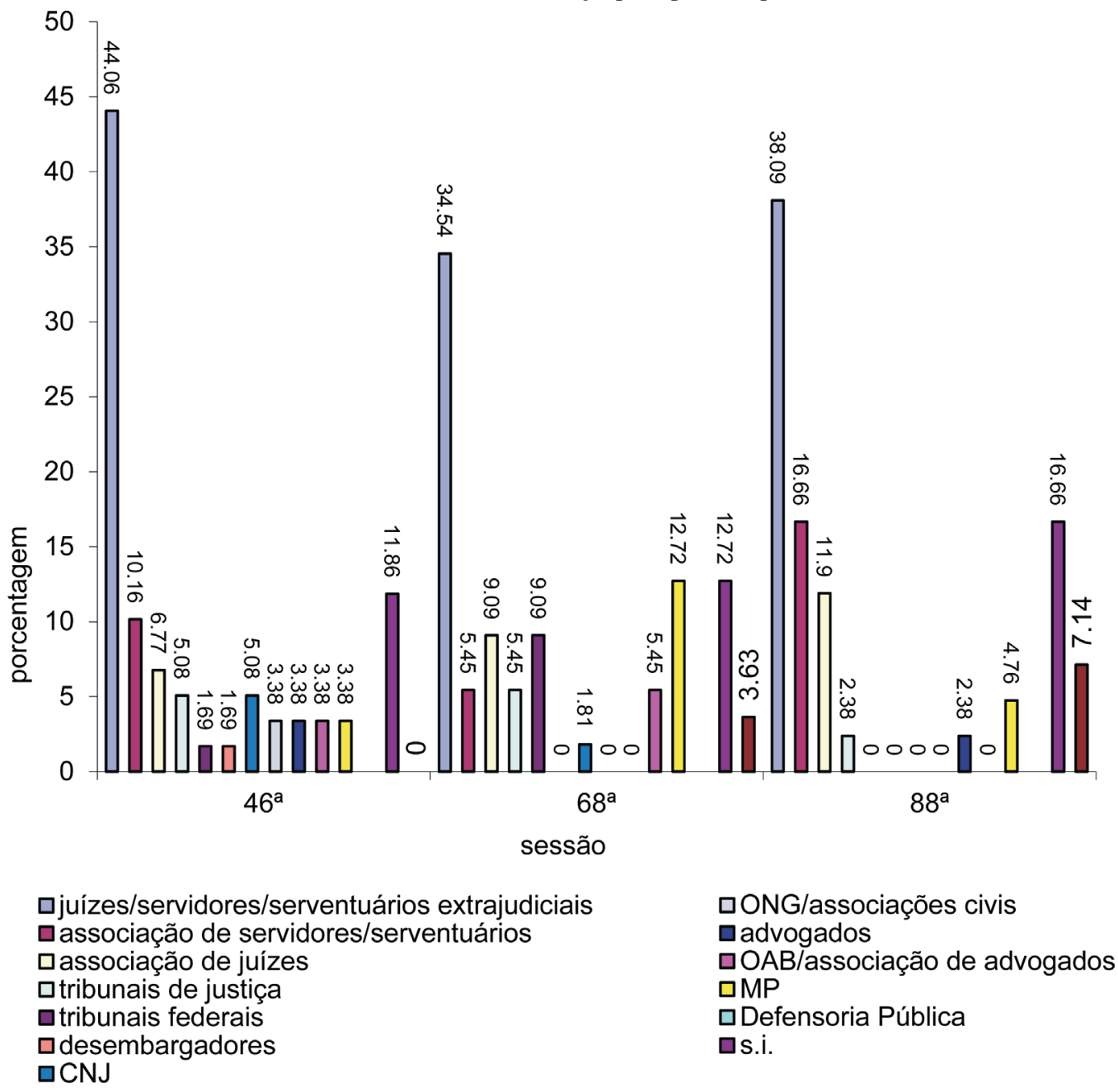

Fonte: Almeida (2010a), a partir de Conselho Nacional de Justiça.

como os conflitos intraprofissionais e interprofissionais em torno da administração e da reforma da justiça brasileira podem ser em grande parte entendidos a partir da diversificação social das bases profissionais das carreiras jurídicas, em oposição à menor variação na composição do pólo dominante do campo jurídico, ainda bastante associado às estruturas tradicionais e aos processos de longo prazo que definiram as relações de poder entre instituições e profissões jurídicas - além dos dados sobre gênero, já expostos (Gráfico 4, acima), dados sobre as faculdades de origem dos membros das elites jurídicas (Gráfico 7 , abaixo) também ilustram essa impermeabilidade relativa do círculo de elites jurídicas em relação aos processos de diversificação social das bases profissionais do campo.

Entre as divisões no interior das elites jurídicas, uma em especial foi de fundamental importância para a análise contida em Almeida 2010a e refere-se a uma quarta orientação dada pela revisão de estudos de elite, concernente à relação entre intelectuais e grupos dirigentes e à própria caracterização dos intelectuais como grupos de poder (Gramsci s.d.; Mannheim 1957; 1986; Bottomore 1965; Miceli 1979; 1999). Quanto a esse aspecto, busquei identificar e analisar o papel dos intelectuais-juristas e de outros especialistas diretamente relacionados à administração da justiça estatal e sua contribuição para a defi- 
9 Sobre o poder dos especialistas na política da justiça, ver o capítulo 5 de minha tese de doutoramento (Almeida 2010a). nição de um discurso e de uma ideologia legítimos para as formas oficiais de oferta de justiça, além de uma agenda para sua reforma9 ${ }^{9}$. O caso dos especialistas em direito processual - associados ao Instituto Brasileiro de Direito Processual e à chamada "Escola Processual Paulista", e com participação recorrente nas principais reformas processuais desde a década de 1970 - é

Gráfico 6 - Porcentagens de procedimentos de controle administrativos e de pedidos de providências, somados, na pauta da $46^{\mathrm{a}}$, da $68^{\mathrm{a}}$ e da $88^{\mathrm{a}}$ sessões ordinárias do Conselho

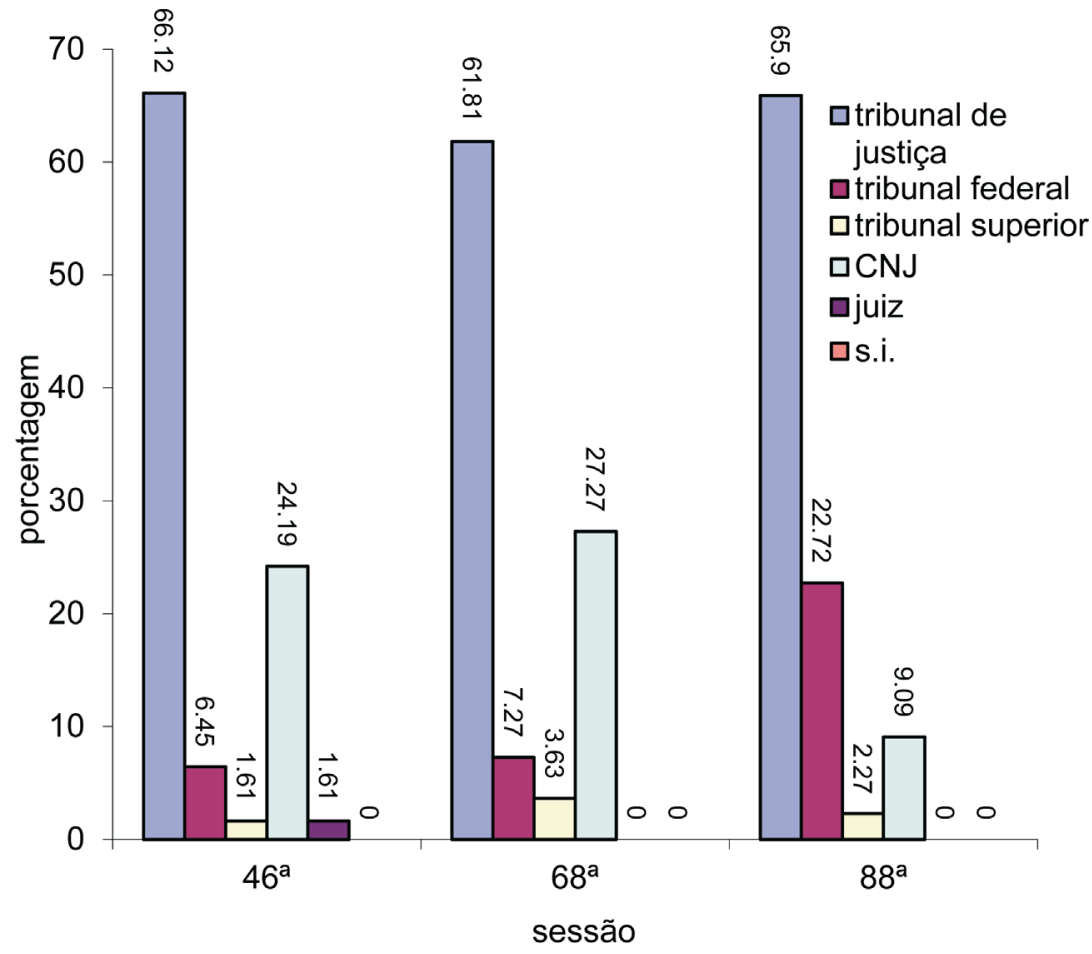

Fonte: Almeida (2010a), a partir de Conselho Nacional de Justiça.

Gráfico 7 - Número de ministros do Supremo Tribunal Federal, por instituição de ensino de origem (Brasil, 1889 a 2008)

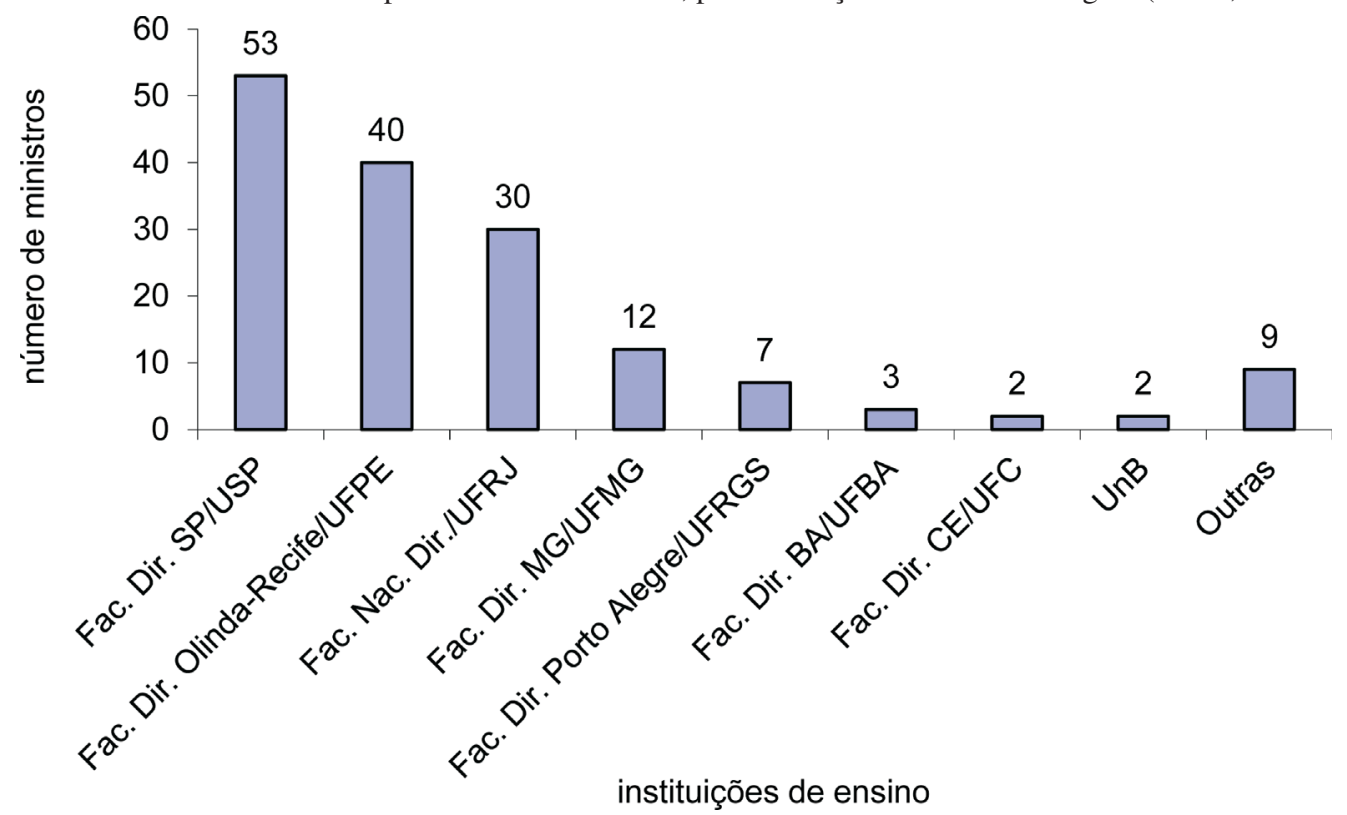

Fontes: Almeida (2010a), a partir de Consultor Jurídico (2008) e Supremo Tribunal Federal. 
Gráfico 8 - Porcentagens de ministros do Supremo Tribunal Federal com títulos de pós-graduação e dedicação à docência (Brasil, 1889-2008)

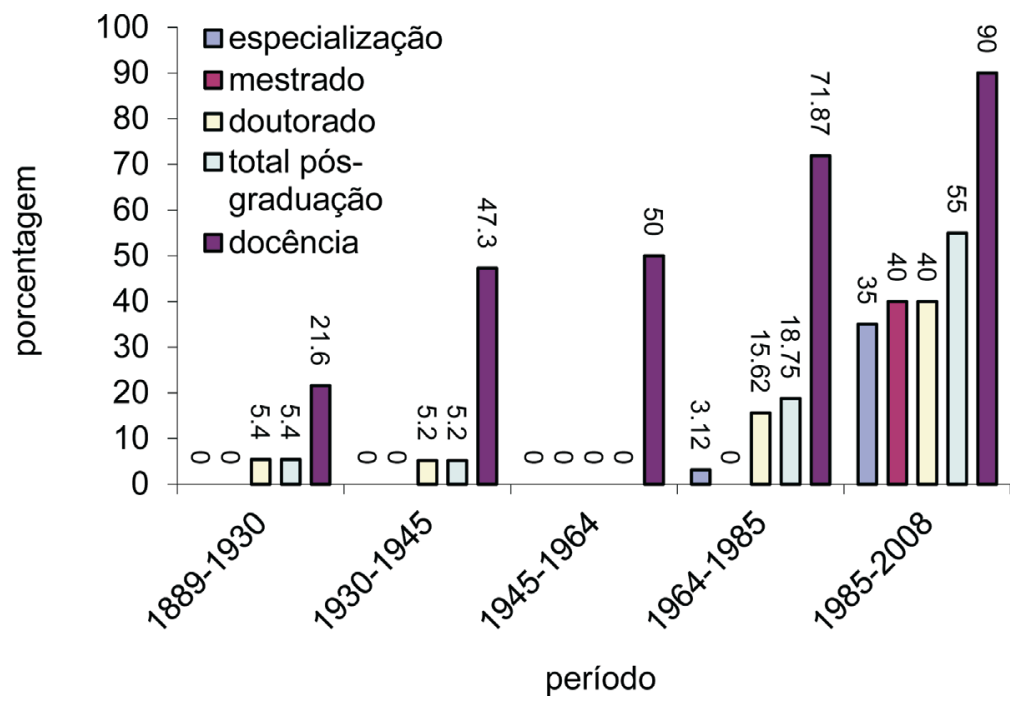

Fonte: Supremo Tribunal Federal.

ilustrativo desse tipo de inserção política de um grupo intelectual na política da justiça.

Uma quinta orientação que vem da tradição dos estudos de elite diz respeito à sua escolarização e ao papel das instituições de ensino no recrutamento, na socialização e na reprodução dos grupos de elite (Gramsci s.d.; Bourdieu 1996; 2007b; Almeida \& Nogueira 2002; Brandão \& Lellis 2003; Bourdieu \& Passeron 2008; Almeida 2009). Considerando-se os diferentes volumes e estruturas de capitais que definem as posições de elite, originalmente derivados da posição social inicial dos agentes do campo (que dessa forma ingressam e se posicionam nos campos, a princípio, apenas pela força de suas heranças familiares, entendidas em sentido amplo), estas podem, contudo, ser alteradas em sua composição interna pelo efeito da entrada de novos grupos no interior do campo, mediada pelo sistema escolar, que passam a disputar com as posições dominantes os recursos próprios de cada campo de poder. De acordo com essa perspectiva, portanto, a diversificação social e política dos campos de poder seria resultado da mediação exercida pelo sistema escolar sobre processos de diferenciação de classe produzidos no âmbito do modo de produção e dos processos de estratificação social decorrentes (Bourdieu 1996; Bourdieu \& Passeron 2008).

Nesse sentido, escolas prestigiadas, voltadas para a instrução de membros das elites sociais, políticas e econômicas, teriam seus diplomas muito valorizados no mercado de especialistas, ao passo que a expansão do mercado de diplomas nas sociedades capitalistas pode ser capaz de reduzir o valor relativo desses diplomas e criar tensões na composição do campo e nas formas de reprodução das estruturas e dos agentes de dominação ao permitir o acesso a esse mercado de grupos socialmente inferiores nas hierarquias e divisões de classes. Da mesma forma, o diploma de uma escola de prestígio pode ser, para um agente socialmente marginal no campo, um importante capital que permita sua ascensão num campo, independente da rede de relações familiares e de seus capitais herdados. Essa seria a chave de análise para se entender as mudanças no interior das elites sociais e políticas (basicamente, as mudanças associadas à sua permeabilidade e à sua composição interna) e, dessa forma, para se compreender a conservação e a mudança na ordem social moderna (Bourdieu 2007b). 
${ }^{10}$ Nesse sentido, ver o capítulo 2 de minha tese de doutoramento (Almeida 2010a); especificamente sobre o valor simbólico dos títulos de pós-graduação, ver também Almeida (2012).
Almeida (2010a) confirmou essa hipótese ao demonstrar que a posse de diplomas superiores de certas faculdades de direito constitui o capital simbólico mais homogeneamente distribuído entre todos os indivíduos e grupos de elite analisados. A análise de currículos e biografias de membros de diferentes grupos das elites jurídicas permitiu identificar um conjunto de faculdades de direito de elite, cujo diploma confere aos seus egressos um acesso privilegiado à administração superior e ao espaço político da reforma da justiça: as faculdades de direito fundadas no Império, as primeiras "escolas livres" fundadas por elites locais nos primeiros anos da República (todas ligadas a universidades públicas, atualmente), e as confessionais católicas (privadas), fundadas nas décadas de 1940 e 1950, seguidas de outros poucos cursos privados laicos criados antes da massificação do ensino na década de 1990 (Gráfico 7). Essa análise também permitiu identificar como a posse de títulos acadêmicos de pós-graduação torna-se um capital diferenciado nas lutas do campo jurídico, mais poderoso quanto maior for a titulação $(\text { Gráfico } 8)^{10}$.

Por fim, ainda no que se refere à sociologia das elites, a opção pelo foco em um processo político conjuntural bastante delimitado no tempo e no espaço - a Reforma do Judiciário, especialmente seu ciclo político de 2003 a 2004 justifica-se a partir da diferenciação entre períodos históricos cruciais, caracterizados por mudanças políticas abruptas (guerras, revoluções, transições de regime etc.), e períodos históricos rotineiros, nos quais as decisões das lideranças políticas ocorrem de acordo com regras ou rotinas estabelecidas, em um contexto de alta previsibilidade (Perissinotto \& Codato 2008). De acordo com essa diferenciação, bastante útil para se dimensionar o papel das elites em processos políticos, "a natureza da elite política é tanto mais importante quanto mais crucial for o período histórico analisado: em momentos de mudança social há mais decisões a tomar, mais opções a fazer, mais alternativas a legitimar" (Perissinotto \& Codato 2008, p. 10).

Meu argumento é que a obtenção de consensos mínimos para a aprovação da Reforma do Judiciário, no período entre 2003 e 2004, após 13 anos de tramitação da Proposta de Emenda Constitucional n. 96/1992 no Congresso Nacional, deveu-se à articulação, pela liderança executiva da Reforma, de grupos de elites jurídicas associados a trajetórias e posições bastante consolidadas no campo jurídico, em torno de uma agenda reformista que acabou por fortalecer as posições do pólo dominante do campo da administração da justiça estatal; nesse sentido, a prevalência da agenda "racionalizadora" (central no resultado final da Reforma e voltada para a centralização do sistema e o aumento de sua eficiência decisória) sobre a agenda "democratizante" (associada à ampliação do acesso à justiça e presente em medidas marginais aprovadas no conjunto das mudanças introduzidas) pode ser explicada pelo protagonismo desses grupos de juristas, cujas trajetórias se associam a processos políticos de longo prazo na estruturação do campo jurídico.

Em suma, acredita-se que a caracterização de um grupo de elite e sua análise sociológica deve levar em conta necessariamente esses cinco fatores - sua relação com a estrutura social, suas divisões e hierarquias internas, sua abertura para a circulação e a permeabilidade, sua escolarização e sua ação política em diferentes tempos históricos; do contrário, o estudo das elites corre o risco da tautologia (explicar a elite por sua já conhecida posição social superior, quando o que se deve explicar é justamente essa posição superior) ou da apologia (simplesmente retratar as elites sem um esforço de análise crítica que desnude as formas de dominação das quais elas são produto, reforçando essa dominação ao expressar acriticamente sua superioridade). 


\section{Conclusões}

O presente trabalho teve por objetivo compartilhar os referenciais teóricos utilizados em minha pesquisa sobre as elites jurídicas e a política da administração da justiça estatal (Almeida 2010a), e a forma pela qual se buscou articulá-los em um esquema analítico mais amplo, por meio da noção de campo jurídico. É a partir dessa moldura teórica que é possível compreender a incidência diferencial e simultânea de elementos explicativos tradicionalmente (e não raro, isoladamente) mobilizados pela sociologia das profissões, pela análise política institucional, pela sociologia das elites em especial, e pela sociologia política em geral. Embora cada uma dessas sociologias específicas tenha seus próprios instrumentais e tradições teóricos, acredito que a articulação de suas contribuições metodológicas no conceito de campo é não só possível, como útil, na medida em que nos permite compreender as elites estatais a partir de elementos que considero essenciais: a origem e a circulação do poder em torno do (mas não necessariamente no) Estado, as formas de divisão social do trabalho e sua institucionalização, os processos de produção e reprodução de elites, e as lógicas específicas dos campos de poder nos quais essas elites atuam preferencialmente.

Frederico de Almeida (fnralmeida @ gmail.com) é Doutor em Ciência Política pela Universidade de São Paulo (USP) e Professor do Departamento de Ciência Política do Instituto de Filosofia e Ciências Humanas da Universidade Estadual de Campinas (Unicamp).

\section{Referências}

Abel, R.L. 1982. The Underdevelopment of Legal Professions: A review article on third world lawyers. American Bar Foundation Research Journal, 7(3), pp. 871-893.

Almeida, A.M.F. 2009. As escolas dos dirigentes paulistas: ensino médio, vestibular, desigualdade social. Belo Horizonte: Argvmentvm.

Almeida, A.M.F.; Nogueira, M.A. 2002. A escolarização das elites: um panorama internacional de pesquisa. $2^{\mathrm{a}}$ ed. Petrópolis: Vozes.

Almeida, F.N.R. 2010a. A nobreza togada: as elites jurídicas e a política da justiça no Brasil. São Paulo. Tese (Doutorado em Ciência Política). Universidade de São Paulo.

. 2010b. Inherited Capital and Acquired Capital: The Socio-Political Dynamics of Producing Legal Elites. Brazilian Political Science Review, 4(2), pp. 32-59.

. 2012. Do profissional-docente ao docente profissional: a valoração simbólica dos títulos acadêmicos e da experiência docente no campo jurídico brasileiro. In E.M. Carvalho, ed. Representações do Professor de Direito. Curitiba: CRV.

Bonelli, M.G. 1999a. Estudos sobre profissões no Brasil. In S. Micelo, ed. O que ler na ciência social brasileira (1970-1995). V. 2. São Paulo: Sumaré.

1999b. As interações dos profissionais do Direito em uma comarca do estado de São Paulo. In M.T.A. Sadek, ed. $O$ sistema de justiça. São Paulo: Idesp/Sumaré.

2002. Profissionalismo e política no mundo do direito: as relações dos advogados, desembargadores, procuradores de justiça e delegados de polícia com o Estado. São Carlos: EdUFSCar/Sumaré.

2003. Perfil social e de carreira dos delegados de polícia. In M.T.A. Sadek, ed. Delegados de polícia. São Paulo: Sumaré.

2008. A magistratura paulista e a resistência à reforma do judiciário. In $32^{\circ}$ Encontro Anual da Anpocs. Caxambu.

Bonelli, M.G.; Oliveira, F.L.; Martins, R. 2006. Profissões jurídicas, identidades e imagem pública. São Carlos: EdUFSCAR.

Bonelli, M.G.; Cunha, L.G.; Oliveira, F.L.; Silveira, M.N.B. 2008. Profissionalização por gênero em escritórios paulistas de advocacia. Tempo Social, 20(1), pp. 265-290.

Bottomore, T.B. 1965 As elites e a sociedade: Rio de Janeiro: Zahar.

Bourdieu, P. 1989. Social Space and Symbolic Power. Sociological Theory, 7(1), pp. 14-25. 1996. The State Nobility. Stanford: Stanford University Press.

2005. Da casa do rei à razão de Estado: um modelo da gênese do campo burocrático. In L. Wacquant, ed. O Mistério do Ministério - Pierre Bourdieu e a política democrática. Rio de Janeiro: Revan.

2007a. O poder simbólico. $10^{\mathrm{a}}$ ed. Rio de Janeiro: Bertrand Brasil.

2007b. Razões práticas: sobre a teoria da ação. $8^{\mathrm{a}}$ ed. Campinas: Papirus.

Bourdieu, P.; Passeron, J.C. 2008. A reprodução: elementos para uma teoria do sistema de ensino. Petrópolis: Vozes.

Brandão, Z.; Lellis, I. 2003. Elites acadêmicas e escolarização dos filhos. Educação e Sociedade, 24(83), pp. 509-526. 
Carvalho, J.M. 2007. A construção da ordem: a elite política imperial. Teatro das sombras: a política imperial. $3^{\mathrm{a}}$ ed. Rio de Janeiro: Civilização Brasileira.

Coelho, E.C. 1999. As profissões imperiais: medicina, engenharia e advocacia no Rio de Janeiro, 1822-1930. Rio de Janeiro: Record.

Cohen, I.J. 1999. Teoria da estruturação e práxis social. In A. Giddens; J. Turner, eds. Teoria social hoje. São Paulo: Ed. UNESP.

Cunha, L.G.S.; Bonelli, M.G.; Oliveira, F.L.; Silveira, M.N.B. 2007. Sociedades de advogados e tendências profissionais. Revista Direito GV, 3(2), p. 111-138.

Cummings, S.L., ed. 2011. The Paradox of Professionalism: Lawyers and the possibility of justice. New York: Cambridge University Press.

Dezalay, Y. 1991. Territorial Battles and Tribal Disputes. The Modern Law Review, 54(6), pp. 792-809.

Dezalay, Y.; Trubek, D. 1996. A Reestruturação global e o Direito - A internacionalização dos campos jurídicos e a criação dos espaços transnacionais. In J.E. Faria, ed. Direito e Globalização Econômica - implicações e perspectivas. São Paulo: Malheiros.

Dezalay, Y.; Garth, B. 2000. A dolarização do conhecimento técnico-profissional e do Estado: processos transnacionais e questões de legitimação na transformação do Estado, 1960-2000. Revista Brasileira de Ciências Sociais, 15(43), pp. $163-176$

2002. La internacionalización de las luchas por el poder: la competencia entre abogados y economistas por transformar los Estados latinoamericanos. Bogotá: ILSA/Universidad Nacional de Colombia.

Diniz, M. 1996. Neomarxistas e Neoweberianos: sobre a natureza do estrato profissional. Dados, 39(1), pp. 101-137.

Ellmann, S. 1992. Client-Centeredness Multiplied: Individual autonomy and collective mobilization in public interest lawyers' representation of groups. Virginia Law Review, 78(5), pp. 1103-1173.

Engelmann, F. 2006a. Sociologia do campo jurídico: juristas e usos do direito. Porto Alegre: Sergio Antonio Fabris. 2006b. Internacionalização e ativismo judicial: as causas coletivas. Lua Nova, 69, pp. 123-146.

Falcão, J. 2005. Estratégias para a Reforma do Judiciário. In S.R.T. Renault; P. Bottini, eds. Reforma do Judiciário. São Paulo: Saraiva.

Ferreira, M.C. 2001. Permeável, ma no troppo? A mobilidade social em setores de elite, Brasil - 1996. Revista Brasileira de Ciências Sociais, 16(47), pp. 141-160.

Freidson, E. 1996. Para uma análise comparada das profissões: a institucionalização do discurso e do conhecimento formais. Revista Brasileira de Ciências Sociais, 31, pp. 141-154. 1998. Renascimento do profissionalismo: teoria, profecia e política. São Paulo: EDUSP.

Giddens, A. 1998. Política, Sociologia e Teoria Social. São Paulo: Ed. UNESP.

Gramsci, A. s.d. Os intelectuais e a organização da cultura. São Paulo: Clube do Livro.

Junqueira, E.B. 1996. Acesso à justiça: um olhar retrospectivo. Revista Estudos Históricos, 18, pp. 389-402.

Heinz, F.M. 2006. O historiador e as elites - à guisa de introdução. In , ed. Por outra história das elites. Rio de Janeiro: FGV.

Heinz, J.P.; Nelson, R.L.; Laumann, E.O. 2001. The Scale of Justice: Observations on the Transformations of the Urban Law Practice. Annual Review of Sociology, 27, pp. 337-362.

Lamaison, P.; Bourdieu, P. 1986. From Rules to Strategies: An Interview with Pierre Bourdieu. Cultural Anthropology, 1(1), pp. 110-120.

Mannheim, K. 1957. Ensayos de sociologia de la cultura. Madrid: Aguilar. 1986. Ideologia e Utopia. Rio de Janeiro: Guanabara.

Miceli, S. 1979. Intelectuais e classe dirigente no Brasil (1920-1945). São Paulo: Difel. 1999. Intelectuais Brasileiros. In S. Miceli, ed. O que ler na ciência social brasileira (1970-1995). V. 2. São Paulo: Sumaré.

2001. Biografia e cooptação (o estado atual das fontes para a história social e política das elites no Brasil). In Intelectuais à brasileira. São Paulo: Companhia das Letras.

Miliband, R. 1999. Análise de classes. In A. Giddens; J. Turner, eds. Teoria social hoje. São Paulo: Ed. UNESP.

Montagner, M.A. 2007. Trajetórias e biografias: notas para uma análise bourdieusiana. Sociologias, 9(17), pp. $204-264$.

Pareto, V. 1966. As elites e o uso da força na sociedade. In A. Souza, ed. Sociologia política. Rio de Janeiro: Zahar.

Perissinotto, R.M.; Codato, A. 2008. Apresentação: por um retorno à Sociologia das Elites. Revista de Sociologia e Política, 16(30), pp. 7-15.

Rueschemeyer, D. 1964. Doctors and Lawyers: A comment on the theory of the professions. Canadian Review of Sociology \& Anthropology, 1(1), pp. 17-30.

1977. The Legal Profession in Comparative Perspective. Sociological Inquiry, 47(3/4), pp. 97-127.

. 1986. Comparing Legal Professions Cross-Nationally: From a professions-centered to a state-centered approach. American Bar Foundation Journal, 11(3), pp. 415-46.

Sadek, M.T.A. 1999. O Sistema de Justiça. In __ ed. O Sistema de Justiça. São Paulo: IDESP/Sumaré. 2001. Controle externo do Poder Judiciário. In ed. Reforma do Judiciário. São Paulo: Fundação Konrad Adenauer. 2002. Estudos sobre o sistema de justiça. In S. Miceli, ed. O que ler na ciência social brasileira. V. 4. São Paulo: Sumaré. 
ed. 2003. Delegados de Polícia. São Paulo: Sumaré.

2004a. El Poder Judicial y la Magistratura como actores políticos. In L.M. Rodrigues; M.T. Sadek, eds. El Brasil de Lula: diputados y magistrados. Buenos Aires: La Crujía.

2004b. Judiciário: mudanças e reformas. Estudos Avançados, 18(51), pp. 79-101. ed. 2006. Magistrados: uma imagem em movimento. Rio de Janeiro: FGV.

Sadek, M.T.A; Arantes, R.B. 2001. Introdução. In M.T.A. Sadek, ed. Reforma do Judiciário. São Paulo: Fundação Konrad Adenauer.

Sadek, M.T.A; Cavalcanti, R.B. 2003. The New Brazilian Public Prosecution: An Agent of Accountability. In S. Mainwaring; C. Welna, eds. Democratic Accountability in Latin America. New York: Oxford University Press.

Sadek, M.T.A; Dantas, H. 2001. Os bacharéis em direito na reforma do Judiciário: técnicos ou curiosos? São Paulo em Perspectiva, 14(2), pp. 101-111.

Sinhoretto, J. 2011. A justiça perto do povo. Reforma e gestão de conflitos. São Paulo: Alameda.

Thiry-Cherques, H.R. 2006. Pierre Bourdieu: a Teoria na Prática. Revista de Administração Pública, 40(1), pp. $27-52$.

Tilly, C. 2004. Itinerários em análise social. Tempo Social, 16(2), pp. 299-302.

Tragtenberg, M. 1974. Burocracia e ideologia. São Paulo: Ática.

Vandenbergue, F. 2006. Construção e critica na nova sociologia francesa. Sociedade e Estado, 21(2), pp. 315-366.

Weber, M. 1972. A política como vocação. In __. Ciência e Política - duas vocações. São Paulo: Cultrix.

Werneck Vianna, L.; Carvalho, M.A.R.; Palácios, M.; Burgos, M. 1997. Corpo e alma da magistratura brasileira. Rio de Janeiro: Revan.

\title{
Outras fontes
}

Consultor Jurídico. 2008. Anuário da Justiça 2008. São Paulo: FAAP/Consultor Jurídico.

\begin{abstract}
This work aims at systematizing the theoretical references used in a study on legal elites and the politics of justice in Brazil. Facing methodological problems brought by empirical research, the article aims at presenting the relations between the sociology of elites, the sociology of legal professions and the political science's institutional analysis on the judicial system, in a way of identifying and analyzing legal elites and their political action in the high administration and in the reform of the Brazilian judicial system. It was possible to establish relations between those theoretical references by facing the conceptions of judicial system and legal field. After reviewing those different theoretical traditions' literature and illustrating the methodological problems by selected sets of data, we can conclude that the notion of legal field is useful as a theoretical framework to understand the institutional, professional and social distinctions and hierarchies which produce elites of judicial politics in Brazil.
\end{abstract}

KEYWORDS: legal elites; judicial politics; judicial system; legal field; judicial reforms. 